The Research Journal of the Costume Culture

[Original Article]

Received December 04, 2016

Revised July 12, 2017

Accepted July 17, 2017

${ }^{\dagger}$ Corresponding author

(dekim@ewha.ac.kr)

ORCID

Mina Jang

http://orcid.org/0000-0001-6839-258X

Dong-Eun Kim

http://orcid.org/0000-0003-1431-9736

This paper is a part of a master's thesis.

\section{A study of preferences and satisfaction levels in maternity and nursing brassieres}

\author{
Mi-Na Jang and Dong-Eun $\mathrm{Kim}^{\dagger}$ \\ Dept. of Fashion Industry, Ewha Womans University, Korea

\section{임산부 및 수유부 전용 브래지어 실태조사와 만족도 연구} \\ 장 미 나 - 김 동 은 $^{+}$ \\ 이화여자대학교 의류산업학과
}

\begin{abstract}
The purpose of this study was to investigate preferences and satisfaction levels in maternity and nursing brassiere. A questionnaire was conducted on 302 women from their $20 \mathrm{~s}$ to $40 \mathrm{~s}$ who had breastfeeding experience. The questionnaire included questions on participant demographics, purchase behavior, and design preference and satisfaction levels. The majority (98.0\%) of the participants had had experience using maternity/nursing brassieres. More than $90 \%$ of the participants agreed with the need for maternity/nursing brassieres distinct from regular ones. Shopping online was the most common means of purchasing them. The most and second-most owned fastener types were the detachable shoulder belt type and inside-cup type, respectively. The most selected reason for purchasing or wearing a maternity/nursing brassiere was the convenience of donning and doffing the brassiere during breastfeeding. Participants had lower satisfaction levels with how well maternity/nursing brassieres support and center the breasts, and with the variety of designs available on the market. Respondents indicated that fasteners for breastfeeding should be developed to provide comfort and convenience for breastfeeding. Wearing comfort was reported as the most important factor in purchasing selection, both during the pregnancy and breastfeeding periods. No-wire, back closure, full-cup, U-shape wing, and skin color were the most preferred design styles.
\end{abstract}

Keywords: maternity(임산부), nursing brassiere(수유브래지어), design satisfaction(디 자인 만족도), fit and size(맞음새 및 치수)

\section{Introduction}

속옷은 여러 가지 목적으로 겉옷 안에 입는 의류의 총칭으로, 착용 범위에 따라 속옷의 종류가 분류된다. 몸매를 잡아주고 형태를 고정시키는 파운데이션, 체온유 지 및 땀이나 분비물을 흡수하는 등의 보건 위생을 목적으로 하는 바디웨어(언더웨 어), 외출 시에 겉옷으로도 입을 수 있는 기능을 하며, 여성 속옷 전체를 지칭하는 란제리의 세 종류로 나눌 수 있다(Lee, 2009). 또한 속옷은 인체에 첫 번째로 입혀 
지는 옷으로 인체구조와 밀접한 관련이 있으며, 체형 의 결점을 보완하고, 인체의 움직임을 보완하는 역할 을 한다. 여성의 경우, 신체 부위 중 피부의 움직임을 고정시켜주는 기능이 가장 필요한 부위는 유방부위 이다(Son, 2006). 여성의 가슴은 나이가 듦에 따라 네 번 정도 변화한다. 10 대에는 가슴이 발달하기 시작하 고, 20 대에는 모든 성장이 끝난 후 절정의 상태가 되 며, 30 대에는 출산과 함께 노화가 시작되어, 40 대 이 후에는 피부 탄력이 저하되고, 몸에서 근육이 빠지기 시작한다. 특히 30 대에는 본격적으로 지방이 축적되 기 시작하는 시기로 대부분의 여성들이 임신이나 출 산, 수유를 겪으면서 가슴 근육이 풀리고, 급격한 체 형 변화가 생긴다. 이렇듯 여성의 신체 중 가슴은 다 른 부위에 비해 변화가 크고, 특히 출산 후에는 가슴 이 아래로 처지기 쉬워 이에 적합한 브래지어를 착용 해 주어야 아름다운 가슴라인을 유지할 수 있다(Ko, 2009; Motherpia, n.d.b).

모유는 아기의 성장과 발달에 가장 적합한 영양으 로, 모유수유를 한 아기는 천식이나 습진 등의 질환 발생을 줄여주며, 중추신경계 발달에 중요한 콜레스 테롤과 DHA가 풍부하게 들어있어 지능을 향상시키 는데 도움이 된다. 또한 모유수유를 한 산모는 산후 우울증의 발생을 감소시키고, 체중 감소 및 골다공증 예방에도 효과적이다(Korean Society of Obstetrics and Gynecology [KSOG], 2007). 2014년 국민건강통계에 따르면 완전모유수유율은 $24.6 \%$ 로 남아가 $22.2 \%$, 여 아가 $27.2 \%$ 였으며 평균 모유수유기간은 9.3 개월로 나타났다. 월령별로는 생후 1 개월에는 완전모유수유 율이 $50.2 \%$, 혼합수유율이 $39.4 \%$ 로 약 $90 \%$ 가 모유 수유를 하는 것으로 나타났다(Kim, 2016). 이에 따라 모유수유의 편리성을 위해 임산부 및 수유부 전용 속 옷을 찾는 소비자 또한 증가하고 있는 추세이다.

Choi, Choi, and Kim(2000)의 연구에서는 수유 브 래지어 생산업체 조사와 소비자 설문조사를 실시하 여 수유 브래지어의 기획 및 생산과 디자인, 기능의 문제점을 분석하였다. 국내 수유 브래지어 업체의 경 우, $\mathrm{D}$ 컵 이상의 제품을 생산하지 않아 수입 제품을 사용할 수밖에 없는 실정이라고 지적하였으며, 설문 조사 결과, 디자인과 수유구의 여밈장치 등이 불만족 요인으로 나타나 수유부들의 체형을 반영하고, 수유 의 편리성을 모두 충족시킬 수 있는 디자인 개발의
필요성을 언급하였다. $\mathrm{Bae}(2002)$ 는 인터뷰와 온라인 판매제품의 비교를 통해 시판되는 수유 브래지어의 현황을 살펴보고, 설문조사를 실시하여 소비자들의 사용 실태를 조사하였다. 수유 브래지어의 불만족 사 항으로는 흡수성, 착탈용이성, 방진성, 트임부위와 어 깨끈의 위치 등으로 나타났으며, 소재의 흡수성과 통 기성 또한 좋지 않다고 조사되어 보다 개선된 기능적 인 수유 브래지어가 개발되어야 할 것으로 평가되었 다. 이와 같이 수유 브래지어에 관한 선행 연구에서 는 수유브래지어의 불만족사항에 관한 조사가 이루 어졌으나, 수유부의 가슴크기와 형태의 변화를 포함 한 최근 실태조사는 이루어지지 않았다.

따라서 본 연구에서는 2차 성징 이후로 유방의 가 장 큰 변화가 생기는 모유수유 시기를 경험한 20 40 대 여성을 대상으로 임산부 - 수유 브래지어의 사용 실태와 만족도 조사를 통해 문제점과 개선 방안을 파 악하여, 보다 나은 임산부 - 수유 브래지어 개발에 필 요한 기초자료를 제공하고자 한다.

\section{Background}

\section{Breast structure}

여성의 유방(breasts)은 유선(mammary gland)이라 고 하는 샘조직과 그 사이사이에 들어 있는 섬유 및 지방조직으로 구성된 기능적이고 복잡한 신체기관이 다(Lee, Park, Lee, \& Park, 2014). 또한 유방은 수유 의 기능 및 생식기의 생리적 주기와 관계가 있으며, 여성의 일생의 주기를 통해서 지속적으로 변화한다 (Lee et al., 2014). 유방은 앞으로 돌출되어 있는 반구 모양으로 앞가슴의 제 2늑골과 제 6 늑골 사이 그리고 흥연골과 정중액와선에 위치한다(Korea Association of Health Promotion, 1998). 유방의 평균 크기는 지 름이 $10 \sim 12 \mathrm{~cm}$ 이고, 두께는 $5 \sim 7 \mathrm{~cm}$ 이며, 지방의 증감 에 따라 유방의 크기가 변할 수 있다(Cho, 2006; Korean Breast Cancer Society [KBCS], 2005). 겉모양으 로는 크게 유두(젖꼭지, nipple), 유륜(젖꽃판, areola), 나머지 부분의 피부로 구분한다(Lee et al., 2014). 유 방의 내부 구조는 실질조직과 이를 지지하는 간질조 직으로 구성되어 있다. 실질조직은 간질조직 사이에 퍼져 있으며, 소실, 소엽, 소엽 내 결합조직으로 구성 되고, 간질조직에는 지방조직, 결체조직, 혈관, 신경, 
림프관 등이 포함된다(KBCS, 2005; Lee, 2002).

여성의 유방은 모유를 생산 - 분비하는 인체의 외 분비기관으로 성장과 발달, 월경주기, 임신과 수유, 폐경 등에 의해 영향을 받으며, 성별이나 나이, 생리 적 상태에 따라 다양하게 변화한다(Lee, 2002; Lee et al., 2014). 특히 임신과 수유기간 동안에는 유방의 선 조직과 유관을 증식시키는 에스트로겐과 유선의 분 비를 가져오는 프로에스트로겐의 영향을 받아 많은 변화를 가져온다(Choung, 1995).

출생 시에는 상피세포에 싸인 몇 개의 유선관만 존 재하며, 젖샘을 만들 흔적기관이 갖추어져 있지는 않 다. 성장하면서 유선관이 증식되고, 9 13세경에 내부 조직의 발달로 인해 유방이 둥글게 부풀어 오른다. 사춘기를 거치면서 유방조직이 성장하고 성숙해져 성 인의 원숙한 유방이 형성된다. 유방의 크기변화는 임 신기간에 현저한 변화가 발생하는데, 높이 항목보다 는 흥부의 너비, 두께, 둘레 및 길이 항목이 점차 증 가하며, 임신 10 개월에 증가 정도가 가장 높다(Chung \& Choi, 1996). 출산 후에는 급격한 호르몬 변화로 인해 젖이 분비되면서 가장 크게 되었다가 수유가 끝 나면 다시 줄어든다(KSOG, 2007; Lee, 2002). 따라서 임신 - 수유 기간 동안 개월 수에 맞는 적합한 브래지 어를 착용해야 이러한 유방의 변화를 방지할 수 있 다. 이후에 유방은 일정한 모양을 유지하다가 나이가 들면서 유선조직이 퇴화하고, 체내지방으로 대치되면 서 피부는 탄력을 잃고 아래로 쳐지게 된다(Lee, 2002).

\section{Design and characteristics of nursing brassiere} 임산부 · 수유 브래지어의 국내 - 외제품의 특성을 살펴보기 위하여 온라인상에서 판매 중인 국내제품 28종, 국외제품 29종을 비교하였다. 검색엔진 네이버
와 구글에서 수유 브래지어, 수유 브라, 너싱 브래지 어 등의 키워드를 이용하여 검색하였을 때, 국내 브 랜드 21 개, 해외 브랜드 9 개로 조사되었다. 그 중 판 매상품이 다양한 브랜드를 각각 6개씩 선정하였으며, 판매순 정렬 결과에 따라 브랜드별 4 5개의 제품을 선택하여 수유 브래지어의 수유구 개폐 방식, 컵스타 일, 와이어 유무, 소재 등에 관한 내용을 조사하였다. 제품을 비교한 결과, 수유 브래지어에서 가장 중요하 게 일반 브래지어와 구분되는 디자인 요소인 수유구 의 개폐 방식(패스너)은 국내 - 외 제품 모두 어깨 수 유구 형태의 디자인이 가장 많은 것으로 나타났다. 어깨 수유구형은 어깨끈과 컵이 이어지는 부분에 플라 스틱으로 된 디테쳐블(detachable) 부자재를 사용한 것으로 수유 시 그 부분을 열어 수유할 수 있도록 디 자인된 브래지어이다(Fig. 1). 그 외에도 어깨 수유구 형과 동일한 형태에서 컵 안쪽에 동그란 구멍이 하나 더 부착된 컵 내부 수유구형, 별도의 부자재 없이 천 을 끌어내려 수유하는 방식의 랩 수유구형, 앞 중심 쪽에 스냅을 이용해 수유할 수 있는 앞 중심 수유구 형 등의 제품이 판매되고 있지만, 앞 중심 수유구 형 태의 수유 브래지어는 최근에는 거의 판매되고 있지 않는 것으로 나타났다. 수유는 매일 수회 실시하고, 수유 시마다 옷을 열어 유방을 드러내게 되므로 유방 을 드러내기 간편해야 하며, 수유가 끝난 뒤에는 다 시 원상태로 되돌아갈 수 있도록 편리한 구조로 되어 야 한다(Shim \& Kim, 2006).

컵 스타일은 국내 제품은 3/4컵이 가장 많았고, 국 외 제품은 스포츠형이 가장 많은 것으로 나타났다. 와 이어 유무는 수유 브래지어의 특성상 국내 - 외제품 모 두 와이어가 없는 제품이 주를 이루었다. 패드주머니 유무 또한 국내 - 외제품 모두 없는 제품이 대부분이

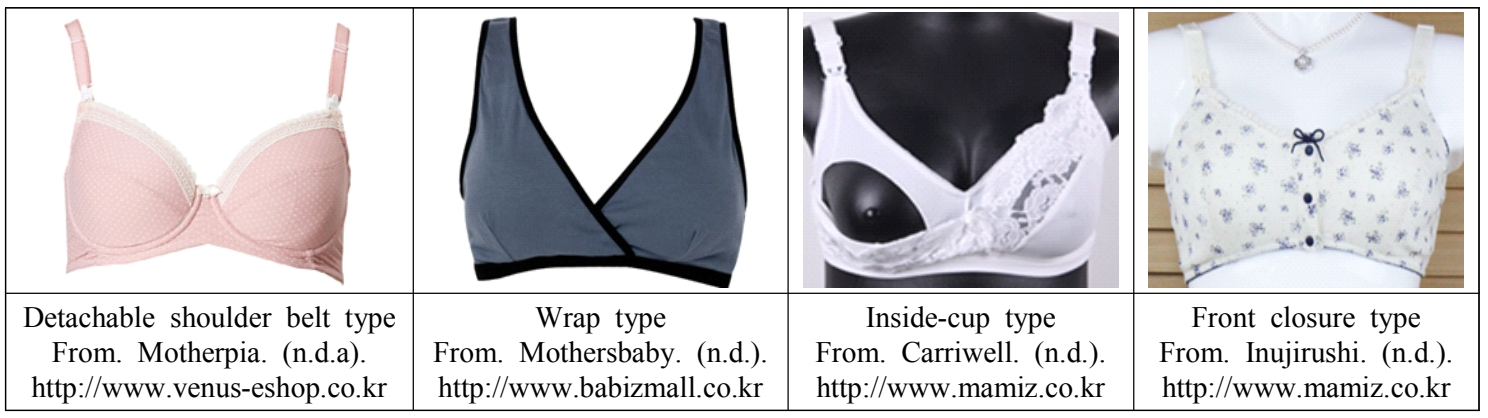

<Fig. 1> Nursing brassiere designs 
었는데, 이는 수유 브래지어의 경우 수유를 하지 않 는 동안에도 모유가 분비되기 때문에 수유패드를 부 착하는데 패드주머니가 있을 경우, 수유패드를 브래 지어 안쪽에 삽입하게 되면 피부가 접촉되는 면에 젖 이 묻을 수 있기 때문으로 보인다. 색상은 국내제품의 경우, 스킨과 핑크 같은 연한색상의 제품들이 많았고, 국외제품은 화이트와 블랙 색상의 제품들이 많은 것 으로 나타났다. 후크 타입은 국내 제품은 일반 브래 지어와 동일한 2후크 6 아이가 가장 많았고, 국외 제 품은 2후크 8 아이가 많은 것으로 나타났으며, 국외 제품이 국내 제품보다 다양한 훅\&아이 타입이 있는 것으로 나타났다. 후크의 폭이 넓을수록 가슴 주변의 군살을 잡아주고, 가슴을 지지하는 효과가 더 크며, 아 이의 수가 늘어날수록 사이즈 조절 폭이 넓어짐을 의 미한다. 수유 브래지어의 경우, 일반 브래지어에 비해 아이의 수가 많은데, 이는 임산부 및 수유부의 경우 가 슴의 사이즈 변화 폭이 크기 때문에, 신체변화에 맞추 어 사이즈 조절이 용이하도록 설계한 것으로 보인다.

수유 브래지어의 사이즈는 국내 제품과 국외 제품 모두 동일하게 70 90까지 다양한 사이즈가 존재했다. 컵 크기는 국내 제품의 경우 $\mathrm{A} \mathrm{E}$ 컵으로 $\mathrm{E}$ 컵의 경우 도 찾아보기 어려웠고, 국외 제품은 $\mathrm{B} \sim \mathrm{H}$ 컵으로 국내 제품보다 컵 사이즈가 다양했다. 또한 랩스타일의 수 유 브래지어는 사이즈를 젖가슴아래둘레와 컵 사이 즈로 구분하지 않고 $\mathrm{M}, \mathrm{L}$ 의 형태로 구분하는 경우도 있었는데, 이 또한 국내 제품보다 국외 제품의 사이 즈 선택 폭이 넓었다. Choi et al.(2000)의 연구에서도 국내업체가 해외업체에 비해 사이즈가 다양하지 못 한 것으로 조사되었으며, $\mathrm{D}$ 컵 이상을 필요로 하는 경 우에는 수입 제품을 착용할 수밖에 없는 실정이라고 지적하였다.

수유 브래지어의 경우, 수유 시 소재가 아기의 피 부에 접촉되기 때문에 어떤 소재를 사용해야 할 지 중요하게 고려해야 하는 부분이다. 피부에 접하는 내 부에는 젖이나 땀을 잘 흡수하고, 신체 알레르기반응 을 최소화 할 수 있는 면으로 된 파일 소재가 많이 사 용되고, 바깥쪽은 신축성이 좋은 스트레치 레이스 또 는 나일론투웨이가 사용된다(Choung, 1995). 국내 · 외 제품의 소재를 비교 해밨을 때, 국내 제품의 경우 면 또는 폴리에스터, 텐셀 등에 폴리우레탄이 혼방된 소재가 많이 사용되고 있었다. 국외 제품은 면 $100 \%$
의 제품도 간혹 찾아볼 수 있었고, 대부분 국내 제품 과 동일하게 면, 폴리에스터, 나일론 등에 폴리우레탄 이 혼방된 소재를 사용하고 있었다.

\section{Methods}

소비자들의 현재 임산부 - 수유 브래지어 착용 시 활동 및 소재에 관한 불편사항, 디자인 만족도와 선 호도 등 사용실태를 조사하기 위해 20 40대의 모유 수유 경험이 있는 여성을 대상으로 설문조사와 인터 뷰를 실시하였다. 임산부·수유 브래지어 마켓조사와 선행 연구를 참고하여 예비 설문지 문항을 작성하였다. 2016년 7월 25일부터 7월 31일까지 모유수유 경험이 있는 여성 30 명을 대상으로 예비 설문조사를 실시하여 총 30 부를 회수하였으며, 예비 설문조사 결과와 인터 뷰 결과를 바탕으로 문제점을 파악하고, 설문 항목의 구체화 및 수정을 통하여 본 조사를 실시하였다.

본 설문기간은 2016년 8월 4일부터 8월 26일까지 23 일간 온라인 설문조사 사이트인 $\mathrm{KSDC}$ 와 오프라인 을 통해 실시하였으며, 회수된 설문지 중 모유수유 경 험이 없다고 응답했거나 응답이 불성실한 32부를 제 외한 302부를 분석에 사용하였다. 설문지는 조사 대 상자의 일반적 특성에 관한 문항 5 개, 모유수유에 관 한 문항 4 개, 수유 브래지어에 관한 문항 11 개, 유방 의 형태 및 사이즈에 관한 문항 3 개, 디자인적 요소에 관한 문항 9 개, 불편사항에 관한 문항 3 개 등 총 35 문 항으로 구성하였으며, 설문조사를 통하여 얻어진 자 료는 SPSS 21.0 for Windows를 사용하여 기술통계, 빈도분석을 실시하였다.

\section{N. Results and Discussion}

\section{Demographic and general information}

조사 대상자의 일반적 특성은 〈Table 1)과 같다. 응답 자 중 출산 후 6 개월 미만인 응답자가 130 명 $(43.0 \%)$ 으로 가장 많았으며, 그 다음으로는 출산 후 6개월 이 상 12 개월 미만 73 명(24.2\%), 12 개월 이상 18 개월 미 만 40 명(13.2\%) 순서로 많았으며, 평균 출산 후 11.5 개월 정도인 것으로 조사되었다.

조사 대상자의 연령은 평균 32.7세로 나타났으며, 30 대가 229명(75.8\%)으로 가장 많았고, 20대 62명(20.5\%), 
<Table 1> Demographic information of participants

\begin{tabular}{|c|c|c|c|}
\hline & Item & $n(\%)$ & $\operatorname{Mean}(S . D)$. \\
\hline \multirow{9}{*}{$\begin{array}{l}\text { Number of } \\
\text { months after } \\
\text { childbirth }\end{array}$} & Less than 6 months & $130(43.0)$ & \multirow{9}{*}{$\begin{array}{c}11.5 \\
(10.3)\end{array}$} \\
\hline & From 6 months to less than 12 months & $73(24.2)$ & \\
\hline & From 12 months to less than 18 months & $40(13.3)$ & \\
\hline & From 18 months to less than 24 months & $22(7.3)$ & \\
\hline & From 24 months to less than 30 months & $14(4.6)$ & \\
\hline & From 30 months to less than 36 months & $14(4.6)$ & \\
\hline & From 36 months to less than 42 months & $8(2.7)$ & \\
\hline & 42 months or more & $1(0.3)$ & \\
\hline & Total & $302(100.0)$ & \\
\hline \multirow{4}{*}{ Age } & $20 \mathrm{~s}$ & $62(20.5)$ & \multirow{4}{*}{$\begin{array}{l}32.7 \\
(4.1)\end{array}$} \\
\hline & $30 \mathrm{~s}$ & $229(75.8)$ & \\
\hline & $40 \mathrm{~s}$ & $11(3.6)$ & \\
\hline & Total & $302(100.0)$ & \\
\hline
\end{tabular}

40대 11명(3.6\%) 순으로 나타났다.

조사 대상자의 신체적 특성은 〈Table 2〉와 같다. 조 사 대상자의 평균 신장은 $160.8 \mathrm{~cm}$, 평균 체중은 $55 \mathrm{~kg}$
인 것으로 나타났다. 설문지 조사가 온라인을 통해 이 뤄졌으므로 직접 계측이 어려워 조사 대상자가 직접 줄자를 이용해 젖가슴둘레와 젖가슴아래둘레를 계측

$<$ Table 2> Physical characteristics of participants

\begin{tabular}{|c|c|c|c|}
\hline \multicolumn{2}{|r|}{ Item } & $n(\%)$ & \multirow[t]{2}{*}{$\operatorname{Mean}(S . D)}$. \\
\hline \multirow{7}{*}{$\begin{array}{l}\text { Bust } \\
\text { circumference }\end{array}$} & Less than $80 \mathrm{~cm}$ & $4(2.1)$ & \\
\hline & From $80 \mathrm{~cm}$ to less than $85 \mathrm{~cm}$ & $25(12.8)$ & \multirow{6}{*}{$\begin{array}{l}89.0 \\
(5.7)\end{array}$} \\
\hline & From $85 \mathrm{~cm}$ to less than $90 \mathrm{~cm}$ & $37(18.9)$ & \\
\hline & From $90 \mathrm{~cm}$ to less than $95 \mathrm{~cm}$ & $83(42.6)$ & \\
\hline & From $95 \mathrm{~cm}$ to less than $100 \mathrm{~cm}$ & $32(16.4)$ & \\
\hline & More than $100 \mathrm{~cm}$ & $14(7.2)$ & \\
\hline & Total & $195(100.0)$ & \\
\hline \multirow{7}{*}{$\begin{array}{l}\text { Underbust } \\
\text { circumference }\end{array}$} & Less than $70 \mathrm{~cm}$ & $7(3.6)$ & \multirow{7}{*}{$\begin{array}{l}77.0 \\
(5.7)\end{array}$} \\
\hline & From $70 \mathrm{~cm}$ to less than $75 \mathrm{~cm}$ & $33(16.9)$ & \\
\hline & From $75 \mathrm{~cm}$ to less than $80 \mathrm{~cm}$ & $67(34.4)$ & \\
\hline & From $80 \mathrm{~cm}$ to less than $85 \mathrm{~cm}$ & $59(30.2)$ & \\
\hline & From $85 \mathrm{~cm}$ to less than $90 \mathrm{~cm}$ & $21(10.8)$ & \\
\hline & More than $90 \mathrm{~cm}$ & $8(4.1)$ & \\
\hline & Total & $195(100.0)$ & \\
\hline
\end{tabular}

Shading is the highest percentage of responses 
하도록 하였으며, 계측 방법은 그림과 설명으로 제시하 였다. 무응답자를 제외한 195 명의 결과만 분석에 사 용하였으며, 조사 대상자의 젖가슴둘레는 평균 $89.0 \mathrm{~cm}$ 로 나타났고, $90 \mathrm{~cm}$ 이상 $95 \mathrm{~cm}$ 미만인 사람이 83 명 (42.6\%)으로 가장 많았다. 젖가슴아래둘레는 평균 77.0 $\mathrm{cm}$ 로 나타났으며, $75 \mathrm{~cm}$ 이상 $80 \mathrm{~cm}$ 미만인 사람이 67 명 $(34.4 \%), 80 \mathrm{~cm}$ 이상 $85 \mathrm{~cm}$ 미만이 59 명 $(30.3 \%)$ 순서 로 많았으며, 평균 브래지어 사이즈는 $75 \mathrm{~B}$ 또는 $80 \mathrm{~B}$ 정도인 것으로 조사되었다. 조사 대상자 중 현재 수유 중인 응답자를 대상으로 젖가슴아래둘레와 착용하는 브래지어 사이즈와의 관계를 알아보기 위하여 교차 분석을 실시하였다. 젖가슴아래둘레 범위는 KS K9404 에 따라 $5 \mathrm{~cm}$ 간격으로 설정하였다. 그 결과, 대부분의 항목에서 착용하는 브래지어 사이즈와 조사 대상자가 직접 계측한 젖가슴아래둘레의 치수가 유사한 것을 알 수 있었다(Table 3). 브레지어 사이즈 75인 21명 중 가장 많은 응답자 $(n=17)$ 가 밑가슴둘레 $72.50 \sim 77.49 \mathrm{~cm}$ 에 분포하였다. 브래지어 사이즈 80 인 60 명 중 21 명 은 밑가슴둘레 $77.50 \sim 82.49 \mathrm{~cm}$ 에, 22명은 $72.50 \sim 77.49 \mathrm{~cm}$ 에 분포하였다. 브래지어 사이즈 85 인 31 명 중 14 명은 $77.50 \sim 82.49 \mathrm{~cm}, 7$ 명은 $82.50 \sim 87.49 \mathrm{~cm}$ 에 분포하였다.

출산 자녀 수를 조사한 결과, 자녀가 1 명인 응답자 가 213 명(70.5\%)으로 가장 많았으며, 그 다음으로는 2 명 이 78명(25.8\%), 3명이 10명(3.3\%), 4명이 1명(0.3\%) 순으로 나타났다. 모유수유 경험 유무에 관한 항목으 로는 현재 수유 중인 응답자가 166명(55.0\%), 수유한 적이 있는 응답자가 136 명(45.0\%)으로 나타났다.
모유수유 기간은 1년 이상인 응답자가 83명(27.5\%) 으로 가장 많았으며, 그 다음으로는 1 개월 이상 3 개 월 미만인 응답자가 63 명(20.9\%), 3개월 이상 6개월 미만인 사람이 56 명(18.5\%), 6개월 이상 9개월 미만 인 사람이 45 명( $14.9 \%)$, 1 개월 미만인 사람이 12 명 (4.0) 순으로 다수의 응답자가 꽤 오랜 기간 모유 수 유를 하는 것으로 나타났다(Table 4).

외출 시 모유수유하는 경우에 관한 항목으로는 자주 있다 라고 응답한 사람이 124 명(41.1\%)으로 가장 높 게 나타났으며, 보통이다 70 명(23.2\%), 매우 자주 있 다 56 명 $(18.5 \%)$ 으로 외출 시 모유 수유하는 경우가 자주 있는 것으로 조사되었다.

외출 시 모유 수유를 못하거나 안 하는 이유에 관한

$<$ Table 4> Breastfeeding period

\begin{tabular}{c|c|c}
\hline Period & $\begin{array}{c}\text { Fre- } \\
\text { quency }\end{array}$ & $\begin{array}{c}\text { Percen- } \\
\text { tage }\end{array}$ \\
\hline Less than 1 months & 12 & 4.0 \\
\hline From 1 month to less than 3 months & 63 & 20.9 \\
\hline From 3 months to less than 6 months & 56 & 18.5 \\
\hline From 6 months to less than 9 months & 45 & 14.9 \\
\hline From 9 months to less than 1 year & 43 & 14.2 \\
\hline 1 year or more & 83 & 27.5 \\
\hline Total & 302 & 100.0 \\
\hline
\end{tabular}

Shading is the highest percentage of responses

<Table 3> Relation between the brassiere size and underbust circumference

\begin{tabular}{|c|c|c|c|c|c|c|c|c|}
\hline & & \multicolumn{6}{|c|}{ Underbust circumference $(\mathrm{cm})$} & \multirow{2}{*}{ Total } \\
\hline & & $67.50 \sim 72.49$ & $72.50 \sim 77.49$ & $77.50 \sim 82.49$ & $82.50 \sim 87.49$ & $87.50 \sim 92.49$ & $92.50 \sim 97.49$ & \\
\hline \multirow{7}{*}{$\begin{array}{c}\text { Brassiere } \\
\text { size }\end{array}$} & 70 & $1(0.8)$ & $1(0.8)$ & $0(0.0)$ & $0(0.0)$ & $0(0.0)$ & $0(0.0)$ & $2(1.6)$ \\
\hline & 75 & $3(2.4)$ & $17(13.6)$ & $1(0.8)$ & $0(0.0)$ & $0(0.0)$ & $0(0.0)$ & $21(16.8)$ \\
\hline & 80 & $7(5.6)$ & $22(17.6)$ & $21(16.8)$ & $8(6.4)$ & $1(0.8)$ & $1(0.8)$ & $60(48.0)$ \\
\hline & 85 & $3(2.4)$ & $5(4.0)$ & $14(11.2)$ & $7(5.6)$ & $2(1.6)$ & $0(0.0)$ & $31(24.8)$ \\
\hline & 90 & $0(0.0)$ & $0(0.0)$ & $3(2.4)$ & $3(2.4)$ & $2(1.6)$ & $0(0.0)$ & $8(\quad 6.4)$ \\
\hline & 95 & $0(0.0)$ & $0(0.0)$ & $0(0.0)$ & $1(0.8)$ & $0(0.0)$ & $1(0.8)$ & $2(1.6)$ \\
\hline & 100 & $0(0.0)$ & $0(0.0)$ & $0(0.0)$ & $1(0.8)$ & $0(0.0)$ & $0(0.0)$ & $1(\quad 0.8)$ \\
\hline \multicolumn{2}{|c|}{ Total } & $14(11.2)$ & $45(36.0)$ & $39(31.2)$ & $20(16.0)$ & $5(4.0)$ & $2(1.6)$ & $125(100.0)$ \\
\hline
\end{tabular}


항목으로는 마땅한 장소가 없어서라고 응답한 사람 이 174 명(57.6\%)으로 가장 높게 나타났다. 옷을 탈의 하기 번거로워서라고 응답한 사람은 53명(17.5\%)으 로 나타났는데, 이는 일반적으로 티셔츠를 입었을 경 우 옷을 아래에서 위로 올려야 하는 구조에 반해 수 유 브래지어는 대부분 위에서 아래로 내려야 하기 때 문으로 사료된다. 기타 응답으로는 외출을 거의 하지 않는다, 외출 시에는 분유로 대체한다 등의 이유로 외출 시 모유 수유를 하지 않는 것으로 조사되었다.

임산부 - 수유 브래지어와 일반 브래지어의 구분 필요성에 대한 조사 결과는 〈Table 5)와 같다. 매우 필 요하다는 응답이 183 명(60.6\%)으로 가장 많았으며, 그 다음으로는 필요하다 100 명 $(33.1 \%)$ 으로 응답자의 $90 \%$ 이상이 임산부 - 수유 브래지어와 일반 브래지 어의 구분이 필요하다고 응답하였다.

일반 브래지어를 착용하고 수유했을 때의 착용 만 족도에 대한 조사 결과는 아주 불편하다는 응답이 138 명 (45.7\%), 불편하다고 응답한 사람이 130 명 $(43.0 \%)$ 으 로 높게 나타나, 응답자의 $80 \%$ 이상이 불편하다는 의 견을 보였다(Table 6).

\section{Purchase behavior of nursing brassiere}

임산부 · 수유 브래지어 착용경험 유무에 관한 항 목으로는 착용해본 적이 있다고 응답한 사람이 296명 $(98.0 \%)$, 착용해본 적이 없다고 응답한 사람이 6 명 (2.0\%)으로 대부분의 사람들이 임산부 - 수유 브래지 어를 착용해본 적이 있는 것으로 나타났다.

임산부 · 수유 브래지어를 주로 구입하는 장소는

$<$ Table 5> The need to distinguish between a regular brassiere and a nursing brassiere

\begin{tabular}{|c|c|c|}
\hline Item & $n(\%)$ & $\operatorname{Mean}(S . D)$. \\
\hline Very necessary & $183(60.6)$ & \multirow{6}{*}{$\begin{array}{c}4.54 \\
(0.63)\end{array}$} \\
\hline Necessary & $100(33.1)$ & \\
\hline Normal & $17(5.6)$ & \\
\hline Not necessary & $2(\quad 0.7)$ & \\
\hline Not necessary at all & $0(\quad 0.0)$ & \\
\hline Total & $302(100.0)$ & \\
\hline
\end{tabular}

Shading is the highest percentage of responses 1 : Not necessary at all $\rightarrow 5$ : Very necessary
$<$ Table 6> Wear satisfaction level when breastfeeding with normal brassiere

\begin{tabular}{c|c|c}
\hline Item & $n(\%)$ & Mean(S.D. $)$ \\
\cline { 1 - 2 } Very uncomfortable & $138(45.7)$ & \\
\cline { 1 - 2 } Uncomfortable & $130(43.0)$ & \\
\cline { 1 - 2 } Normal & $22(7.3)$ & \multirow{2}{*}{$\left.\begin{array}{c}1 \\
(0.71\end{array}\right)$} \\
\cline { 1 - 2 } Comfortable & $9(3.0)$ & \\
\cline { 1 - 2 } Very comfortable & $3(1.0)$ & \\
\hline Total & $302(100.0)$ & \\
\hline
\end{tabular}

Shading is the highest percentage of responses 1 : Very uncomfortable $\rightarrow 5$ : Very comfortable

$<$ Table 7> Purchasing place of maternity and nursing brassiere

\begin{tabular}{c|c|c}
\hline Place & Frequency & Percentage \\
\hline Department store & 58 & 19.6 \\
\hline Discount store & 21 & 7.1 \\
\hline Internet(online shoppingmall) & 173 & 58.4 \\
\hline Home shopping & 2 & 0.7 \\
\hline Market & 4 & 1.4 \\
\hline Mart & 12 & 4.1 \\
\hline Other & 26 & 8.8 \\
\hline Total & 296 & 100.0 \\
\hline
\end{tabular}

Shading is the highest percentage of responses

인터넷(온라인쇼핑몰)이 173 명(58.4\%)으로 높게 나 타났으며, 그 다음으로는 백화점 58 명(19.6\%)으로 나 타났다. 기타 의견으로는 베이비 페어에서 구입한 사 람이 상당수인 것으로 조사되었다(Table 7).

〈Table 8〉은 보유하고 있는 임산부 · 수유 브래지 어 패스너(개폐 부위) 형태에 대한 조사 결과이다. 어 깨수유구형을 보유하고 있다는 응답이 177명(36.0\%) 으로 가장 많았으며, 컵내부 수유구형이 161명(32.7\%) 으로 어깨수유구형과 비슷한 비율로 나타났다. 앞중 심 수유구형의 경우, 35 명(7.1\%)으로 응답률이 낮았는 데, 이는 시판 중인 제품 중 앞중심 수유구 형태의 수 유 브래지어를 구매하기 힘들기 때문으로 사료된다.

임산부 · 수유 브래지어의 적당한 가격대에 관한 항 
$<$ Table 8> Fastener design of maternity/nursing brassiere that participants own

Detachable shoulder belt type

Shading is the highest percentage of responses

*Multiple response question

목으로는 1 만 원 이상 3 만 원 이하의 응답이 220 명 $\mathbf{( 7 4 . 3 \% )}$ 으로 가장 높게 나타났다. 수유 브래지어의 착용 기간이 짧은 만큼 비교적 저렴한 가격대를 선호 하는 것으로 사료된다.

임신 산후 기간 중 체형 변화로 인해 새로 구입 한 임산부 - 수유 브래지어의 개수에 관한 항목으로 는 5 개 이상 구매하였다는 응답이 91명 $(30.7 \%)$ 으로 가장 많았으며, 3개가 87명(29.4\%), 4개가 70명(23.6\%) 으로 대부분 3 개 이상 구매하는 것으로 조사되었다. $\mathrm{Bae}$ (2002)의 연구에 의하면 수유브래지어 평균 소지 개수가 2개였던 것에 반해 많이 늘었는데, 그만큼 모 유수유를 하는 사람이 늘어났고, 수유 브래지어의 필 요성이 중요시된 것으로 해석할 수 있다.

〈Table 9〉는 임산부 - 수유 브래지어를 구입 또는 착용한 이유에 대한 조사 결과이다. 수유 시 브래지어 착 - 탈의 편리성을 위해서라는 응답이 226명(76.4\%) 으로 가장 많았으며, 그 다음으로는 가슴이 커져 일 반 브래지어의 사이즈가 맞기 않아서라고 응답한 사 람이 55명(18.6\%)으로 나타났다. 기타 의견으로는 수 유 시 브래지어 착 - 탈의 편리성을 위해서와 가슴이 커져 일반브래지어의 사이즈가 맞지 않아서의 중복 적인 이유로 수유 및 임산부 전용 브래지어를 구입했 다고 응답하였다.

임산부 - 수유 브래지어를 구입하지 않는다고 응답 한 6명에 대한 조사 결과, 필요성을 못 느껴서, 착용 기간이 짧아 비경제적이어서, 제품에 대한 정보를 잘
$<$ Table 9> Purchasing or wearing reason of maternity and nursing brassiere

\begin{tabular}{l|r|r}
\hline Reason & $\begin{array}{c}\text { Fre- } \\
\text { quency }\end{array}$ & $\begin{array}{c}\text { Percen- } \\
\text { tage }\end{array}$ \\
\hline $\begin{array}{l}\text { For the convenience of donning and do- } \\
\text { ffing the brassiere during breastfeeding }\end{array}$ & 226 & 76.4 \\
\hline To absorb sweat and breast milk & 5 & 1.7 \\
\hline $\begin{array}{l}\text { The size of regular brassiere is not right, } \\
\text { because the breast has become bigger }\end{array}$ & 55 & 18.6 \\
\hline To prevent sagging of the breast & 0 & 0.0 \\
\hline Other & 10 & 3.4 \\
\hline Total & 296 & 100.0 \\
\hline
\end{tabular}

Shading is the highest percentage of responses

몰라서, 디자인이 마음에 들지 않아서 등 다양한 이 유로 수유 및 임산부 전용 브래지어를 구입하지 않은 것으로 조사되었다.

임산부 - 수유 브래지어의 주요 착용 장소에 대한 조사 결과는 어디서나 항상 착용한다는 응답이 194명 (65.5\%)으로 가장 많았으며, 그 다음으로는 자택(21.6\%), 기타 의견으로는 외출 시에만 착용하는 것으로 조사 되었다. 임산부 - 수유 브래지어의 착용 횟수에 관한 항목으로는 매일 착용한다는 응답이 228 명(77.0\%)으 로 압도적으로 높게 나타났다.

임신 및 수유에 따른 브래지어 사이즈 변화에 관한 
문항에서는 대부분의 응답자가 사이즈 변화가 있었 다고 응답하였다. 임신 전 사이즈의 경우, $80 \mathrm{~A}(12.2 \%)$, $80 \mathrm{~B}(15.2 \%), 75 \mathrm{~B}(12.3 \%)$ 순으로 나타났으며, 임신 중 사이즈 $80 \mathrm{~B}(21.5 \%), 80 \mathrm{~A}(13.2 \%)$, 수유 중 사이즈 $80 \mathrm{~B}$ (18.2\%), 80C(13.2\%), 수유 후 사이즈 80A(26.7\%), $80 \mathrm{~B}(10.2 \%)$ 순으로 조사되었다. 사이즈 변화를 살펴 보면, 임신 전과 임신 중에 비해 수유 중 사이즈가 한 컵 정도 커진 것을 알 수 있으며, 수유 후 원래의 사 이즈로 돌아간 것을 알 수 있었다.

〈Table 10〉은 임신 및 수유 여부에 따른 유방 형태 변화에 대한 조사 결과이다. 임신 전 원추형 $(52.0 \%)$, 임신 중 원추형 $(56.3 \%)$ 이라고 응답한 사람이 $50 \%$ 이 상인 것으로 나타났다. 수유 중 유방의 형태는 원추형 (29.1\%), 돌출형(28.8\%)으로 수유로 인해 가슴의 사 이즈가 커지면서 가슴의 형태 또한 변화한 것으로 조 사되었다. 수유 후 유방의 형태는 하수형 I 이라고 응 답한 사람이 59명(33.5\%)으로 가장 높게 나타났는데, 수유로 인해 가슴이 무거워지고, 대부분의 수유 브래 지어가 와이어가 없기 때문에 가슴을 받쳐주는 힘이 부족하기 때문으로 사료된다.

임산부 - 수유 브래지어 선호 브랜드에 대한 조사 결과, 마더스베이비(17.8\%), 비비안(16.2\%), 마더피 아(15.7\%), 비너스 마터니티(11.3\%) 순으로 나타났으 며, 기타 응답으로는 세컨스킨, 유니클로를 선호한다 는 응답과 브랜드가 없는 제품을 선호한다는 응답이 많았다.

임산부·수유 브래지어 구매 시 고려 요인으로는
수유기간 동안(44.7\%), 임신기간 동안(50.7\%) 모두 착용감이 가장 중요하게 고려하는 요소로 나타났다 (Table 11). 그 다음 중요한 요인으로는 수유기간 동

$<$ Table 11> Factors to consider when purchasing maternity and nursing brassiere

$n(\%)$

\begin{tabular}{|c|c|c|}
\hline Item & $\begin{array}{c}\text { During } \\
\text { breastfeeding }\end{array}$ & $\begin{array}{c}\text { During } \\
\text { pregnancy }\end{array}$ \\
\hline Brand awareness & $5(1.7)$ & $9(3.0)$ \\
\hline Wearing comfort & $135(44.7)$ & $153(50.7)$ \\
\hline Quality & $7(2.3)$ & $12(4.0)$ \\
\hline Price & $16(5.3)$ & $19(6.3)$ \\
\hline Suitable size for my body & $16(5.3)$ & $38(12.6)$ \\
\hline Design & $1(0.3)$ & $11(3.6)$ \\
\hline Durability & $3(1.0)$ & $2(0.7)$ \\
\hline Activity & $6(2.0)$ & $14(4.6)$ \\
\hline $\begin{array}{l}\text { Makes visually better } \\
\text { breast shape }\end{array}$ & $7(2.3)$ & $16(5.3)$ \\
\hline Size(Fit of brassiere) & $5(1.7)$ & $19(6.3)$ \\
\hline Convenience of fastener & $93(30.8)$ & $4(1.3)$ \\
\hline Convenience of Purchase & $2\left(\begin{array}{ll}0.7\end{array}\right)$ & $4(1.3)$ \\
\hline Other & $6(2.0)$ & $1(0.3)$ \\
\hline Total & $302(100.0)$ & $302(100.0)$ \\
\hline
\end{tabular}

Shading is the highest percentage of responses

$<$ Table 10 $>$ Changes in breast shape due to pregnancy and breastfeeding

\begin{tabular}{|c|c|c|c|c|c|c|c|}
\hline Breast shape & Flat & $\underbrace{}_{\text {Conical }}$ & 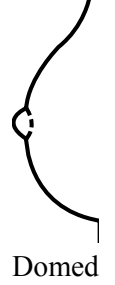 & Projecting & $\underbrace{}_{\text {Drooping I }}$ & Drooping II & Total \\
\hline Before pregnancy & $40(13.2)$ & $157(52.0)$ & $77(25.5)$ & $13(4.3)$ & $14(4.6)$ & $1(0.3)$ & $302(100.0)$ \\
\hline During pregnancy & $3(1.0)$ & $170(56.3)$ & $81(26.8)$ & $33(10.9)$ & $15(5.0)$ & $0(0.0)$ & $302(100.0)$ \\
\hline During breastfeeding & $2(0.7)$ & $88(29.1)$ & $55(18.2)$ & $87(28.8)$ & $62(20.5)$ & $8(2.6)$ & $302(100.0)$ \\
\hline After breastfeeding & $30(17.0)$ & $22(12.5)$ & $17(9.7)$ & $27(15.3)$ & $59(33.5)$ & 21(11.9) & $176(100.0)$ \\
\hline
\end{tabular}

Shading is the highest percentage of responses 
안에는 패스너(개폐 부위)의 편리성(30.8\%) 임신기간 동안은 내 몸에 적합한 호칭(12.6\%)으로 나타났다(Table 11). 임신 또는 수유를 하게 되면 유방부위가 민감해 지므로 브래지어를 착용했을 때 가슴을 압박하지 않 으며, 착용감이 좋은 제품을 선호하는 것으로 사료된다. 또한 수유기간 동안에는 패스너(개폐 부위)의 편리성 을 고려하는 것으로 나타났는데, 이는 수유 시 아기 에게 젖을 빨리 물리기 위해서는 수유구의 개폐 방법 이 편리해야 빠르게 열 수 있기 때문으로 해석된다.

\section{Design preferences and satisfaction}

임산부·수유 브래지어의 구성 요소별 디자인 선 호도는 와이어 유무, 여밈 형태, 컵 스타일, 뒷면(날 개) 모양, 색상으로 나누어 조사하였으며, 그 결과는 〈Table 12〉와 같다. 와이어 유무로는 와이어가 없는 디자인(87.7\%)이 앞도적으로 높게 나타났는데, 와이 어가 있는 경우, 유방을 압박하여 착용감이 좋기 않기 때문에 와이어가 없는 제품을 더욱 선호하는 것으로 사료된다. 여밈 형태에 대한 응답은 일반적인 브래지 어 형태의 뒤 여밈 $(50.0 \%)$ 이 가장 많았으며, 앞 여밈 $(32.8 \%)$, 여밈 없음 $(17.2 \%)$ 순으로 나타났다. 컵 스타일 관련 문항은 풀-컵(38.7\%), 3/4컵(36.4\%)으로 가슴을 많이 감싸는 형태의 디자인을 선호하는 것으로 조사 되었다. 뒷면(날개) 모양은 U자형이 143명(47.4\%)으 로 가장 많았으며, 그 다음으로는 일자형 $(29.5 \%)$, 탱 크탑형 $(23.2 \%)$ 순으로 나타나, 가슴을 가장 잘 지지해 줄 수 있는 U자형의 디자인을 가장 선호하는 것을 알 수 있었다. 색상에 관한 문항의 조사결과 스킨색이 261 명(86.4\%)으로 압도적으로 높게 나타났으며, 기타 응답으로는 색상이 무관하다는 응답이 있었다.

임산부 - 수유 브래지어 선호 소재와 관련한 문항의 조사결과, 가장 선호하는 소재는 면(30.5\%)이었으며, 그 다음으로는 면+스판덱스(29.1\%), 유기농 면(25.9\%) 순으로 나타나, 면이 들어간 소재를 선호하는 것으로 조사되었다. 수유 및 임산부 전용 브래지어 패스너(개 폐 부위) 선호도에 관한 문항 조사결과, 어깨수유구형 이 127 명(42.1\%)으로 가장 높게 나타났으며, 그 다음 으로는 컵 내부 수유구형(28.1\%), 랩형(25.8\%) 순으 로 나타나, 앞중심 수유구형(4.0\%)이 가장 낮은 선호 도를 보였다.

〈Table 13〉은 임산부 - 수유 브래지어 사용시 만족
도에 대한 조사 결과이다. 가슴을 잘 받쳐준다, 가슴 을 잘 모아준다, 디자인이 다양하다 항목에서 보통(3점) 미만의 낮은 만족도를 보였으며, 가장 낮은 만족도는 2.53으로 디자인이 다양하다는 항목이었다. 이는 시 장조사에서 나타난 바와 같이 대부분의 디자인이 무 늬가 없으며, 살색, 핑크색, 검정색 등으로 한정적이

$<$ Table 12> Design preference of maternity and nursing brassiere styles

\begin{tabular}{|c|c|c|c|}
\hline \multicolumn{2}{|c|}{ Item } & Frequency & Percentage \\
\hline \multirow{3}{*}{$\begin{array}{c}\text { Wire } \\
\text { existence }\end{array}$} & Wire & 37 & 12.3 \\
\hline & No-wire & 265 & 87.7 \\
\hline & Total & 302 & 100.0 \\
\hline \multirow{4}{*}{$\begin{array}{l}\text { Closure } \\
\text { location }\end{array}$} & Front & 99 & 32.8 \\
\hline & Back & 151 & 50.0 \\
\hline & None & 52 & 17.2 \\
\hline & Total & 302 & 100.0 \\
\hline \multirow{6}{*}{$\begin{array}{c}\text { Cup } \\
\text { shape }\end{array}$} & Full-cup & 117 & 38.7 \\
\hline & $3 / 4$ cup & 110 & 36.4 \\
\hline & $1 / 2$ cup & 15 & 5.0 \\
\hline & Sport & 32 & 10.6 \\
\hline & Bra top & 28 & 9.3 \\
\hline & Total & 302 & 100.0 \\
\hline \multirow{4}{*}{$\begin{array}{l}\text { Wing } \\
\text { shape }\end{array}$} & $\mathrm{U}$ & 143 & 47.4 \\
\hline & Straight & 89 & 29.4 \\
\hline & Tank top & 70 & 23.2 \\
\hline & Total & 302 & 100.0 \\
\hline \multirow{8}{*}{ Color } & White & 10 & 3.3 \\
\hline & Skin & 261 & 86.4 \\
\hline & Black & 17 & 5.7 \\
\hline & Pink & 7 & 2.3 \\
\hline & Red & 1 & 0.3 \\
\hline & Blue & 2 & 0.7 \\
\hline & Other & 4 & 1.3 \\
\hline & Total & 302 & 100.0 \\
\hline
\end{tabular}

Shading is the highest percentage of responses 
$<$ Table 13> Satisfaction level when using maternity and nursing brassiere

$(N=302)$

\begin{tabular}{l|c|c|c|c|c|c}
\hline \multicolumn{1}{c|}{ Variable } & \multirow{2}{*}{$\begin{array}{c}\text { Mean } \\
\text { (S.D. }\end{array}$} & \multicolumn{5}{c}{ Rating scale $n(\%)$} \\
\cline { 5 - 7 } & & 1 & 2 & 3 & 4 & 5 \\
\hline Overall size is good. & $3.53(0.90)$ & $11(3.6)$ & $14(4.6)$ & $117(38.7)$ & $124(41.1)$ & $36(11.9)$ \\
\hline Absorb sweat or breast milk well & $3.43(0.89)$ & $10(3.3)$ & $20(6.6)$ & $132(43.7)$ & $109(36.1)$ & $31(10.3)$ \\
\hline It is convenient to replace the pad. & $3.59(0.99)$ & $8(2.6)$ & $36(11.9)$ & $81(26.8)$ & $125(41.4)$ & $52(17.2)$ \\
\hline $\begin{array}{l}\text { It is convenient to open and close fasteners } \\
\text { when breastfeeding. }\end{array}$ & $3.88(0.95)$ & $9(3.0)$ & $16(5.3)$ & $55(18.2)$ & $144(47.7)$ & $78(25.8)$ \\
\hline Back or front closure is convenient & $3.64(0.91)$ & $9(3.0)$ & $17(5.6)$ & $95(31.5)$ & $134(44.4)$ & $47(15.6)$ \\
\hline The seam does not stimulate the nipple. & $3.67(0.91)$ & $8(2.6)$ & $17(5.6)$ & $92(30.5)$ & $134(44.4)$ & $51(16.9)$ \\
\hline Shoulder straps don't compress skin. & $3.56(0.93)$ & $8(2.6)$ & $26(8.6)$ & $101(33.4)$ & $124(41.1)$ & $43(14.2)$ \\
\hline Supports breast well & $2.72(1.00)$ & $34(11.3)$ & $90(29.8)$ & $119(39.4)$ & $45(14.9)$ & $14(4.6)$ \\
\hline Converge breast to the center & $2.56(0.98)$ & $39(12.9)$ & $109(36.1)$ & $112(37.1)$ & $29(9.6)$ & $13(4.3)$ \\
\hline Variety of designs available on the market & $2.53(0.95)$ & $46(15.2)$ & $97(32.1)$ & $120(39.7)$ & $32(10.6)$ & $7(2.3)$ \\
\hline
\end{tabular}

Shading is items with low satisfaction

1 : Very dissatisfied $\rightarrow 5$ : Very satisfied

기 때문으로 사료된다. 수유 브래지어의 경우, 패드와 와이어가 없는 제품이 대부분으로 가슴을 받쳐주고 모 아주는 기능이 떨어지며, 인터뷰 시에도 지적되었던 사 항으로 브래지어 컵의 형태가 고정되지 않아 불편해서 사용하지 않으며, 가슴이 처질까봐 염려되어 와이어 가 있는 일반 브래지어를 착용한다는 의견이 있었다.
임산부 - 수유 브래지어의 착용 효과별 중요도는 〈Table 14〉와 같다. 가장 필요한 착용 효과 중요도를 보인 항목은 수유 시 패스너 열고 닫기 항목이었으며, 그 다음으로는 유방 압박하지 않기, 땀이나 젖 흡수 하기, 유방 받쳐주기 등의 항목이 중요도가 높은 것 을 알 수 있다. 수유 시 가장 중요한 항목은 패스너

$<$ Table 14> Importance by wearing effect of maternity and nursing brassiere

$(N=302)$

\begin{tabular}{l|c|c|c|c|c|c}
\hline \multicolumn{1}{c|}{ Variable } & \multirow{2}{*}{$\begin{array}{c}\text { Mean } \\
\text { S.D. }\end{array}$} & \multicolumn{5}{c}{ Rating scale n(\%) } \\
\cline { 5 - 7 } & & 1 & 2 & 3 & 4 & 5 \\
\hline Make a natural breast shape. & $3.77(0.88)$ & $8(2.6)$ & $14(4.6)$ & $68(22.5)$ & $160(53.0)$ & $52(17.2)$ \\
\hline Make the breast look plump & $2.65(1.09)$ & $45(14.9)$ & $98(32.5)$ & $94(31.1)$ & $47(15.6)$ & $18(6.0)$ \\
\hline Prevent shaking of the breast & $3.94(0.85)$ & $4(1.3)$ & $13(4.3)$ & $57(18.9)$ & $152(50.3)$ & $76(25.2)$ \\
\hline Supporting breast & $4.20(0.75)$ & $2(0.7)$ & $3(1.0)$ & $39(12.9)$ & $147(48.7)$ & $111(36.8)$ \\
\hline Do not compress breast & $4.43(0.69)$ & $1(0.3)$ & $3(1.0)$ & $20(6.6)$ & $119(39.4)$ & $159(52.6)$ \\
\hline Supports side flab & $3.62(1.02)$ & $9(3.0)$ & $25(8.3)$ & $106(35.1)$ & $94(31.1)$ & $68(22.5)$ \\
\hline Open and close fasteners when breastfeeding & $4.49(0.70)$ & $1(0.3)$ & $3(1.0)$ & $22(7.3)$ & $98(32.5)$ & $178(58.9)$ \\
\hline Absorb sweat and breast milk & $4.42(0.76)$ & $2(0.7)$ & $3(1.0)$ & $29(9.6)$ & $99(32.8)$ & $169(56.0)$ \\
\hline
\end{tabular}

Shading is items with high importance

1 : Not necessary at all $\rightarrow 5$ : Very necessary 
$<$ Table 15> Most necessary wear effect of maternity and nursing brassiere

\begin{tabular}{l|c|c}
\hline Factor & Frequency & Percentage \\
\hline Make a natural breast shape & 22 & 7.3 \\
\hline Make the breast look plump & 5 & 1.7 \\
\hline Prevent shaking of the breast & 12 & 4 \\
\hline $\begin{array}{l}\text { Supporting breast } \\
\text { Do not compress breast }\end{array}$ & 48 & 15.9 \\
\hline Supports side flab & 5 & 21.2 \\
\hline $\begin{array}{c}\text { Open and close fasteners } \\
\text { when breastfeeding }\end{array}$ & 105 & 34.8 \\
\hline Tbsorb sweat and breast milk & 41 & 13.6 \\
\hline & 302 & 100.0 \\
\hline
\end{tabular}

Shading is the highest percentage of responses

열고 닫기로 현재 시판되는 형태의 패스너보다 더욱 편리한 패스너의 개발이 요구되며, 땀과 젖 흡수가 용이한 소재를 사용이 중요하다.

위의 문항 중 임산부 · 수유 브래지어의 가장 필요한 착용 효과는 수유 시 패스너 열고 닫기라고 응답한 사람 이 105 명(34.8\%)으로 가장 높게 나타났다(Table 15).

〈Table 16〉은 임산부 · 수유 브래지어의 불편 부위 및 개선이 필요한 부위에 관한 문항으로 와이어 부위 가 153 명 $(21.1 \%)$ 으로 가장 많았으며, 컵 밑받침과 날 개 연결부위(13.0\%), 컵 부위(12.7\%) 순으로 나타나, 와이어의 개선이 필요할 것으로 조사되었다. 기타 응 답으로는 세탁 후 보풀이 생긴다, 컵 부위의 소재 개 선, 유두를 지나가는 수유 끈의 문제점을 지적하였다.

\section{Conclusion}

모유수유의 장점이 강조되면서 모유수유율이 증가 하고 있고, 보다 편리한 수유를 위해 임산부 - 수유 브래지어를 찾는 소비자들이 늘어나고 있다. 하지만 수유기간이 짧아 비경제적이며, 임산부 · 수유 브래지 어의 디자인이 다양하지 못한 실정이다. 따라서 본 연구에서는 더 나은 임산부 - 수유 브래지어 개발을 위하여, 수유부를 대상으로 임산부·수유 브래지어 착의 실태 및 만족도를 조사하였다.
$<$ Table 16> Part to discomfort and needed improvement of maternity and nursing brassiere

\begin{tabular}{l|c|c}
\multicolumn{1}{c|}{ Parts } & Frequency & Percentage \\
\hline Cup & 92 & 12.7 \\
\hline Wire & 153 & 21.1 \\
\hline Cradle and wing connection & 94 & 13.0 \\
\hline Wing & 22 & 3.0 \\
\hline Band & 35 & 4.8 \\
\hline Hook \& eye & 88 & 12.1 \\
\hline Shoulder strap & 96 & 13.2 \\
\hline Centre piece & 46 & 6.3 \\
\hline Fastener & 87 & 12.0 \\
\hline Other & 12 & 1.7 \\
\hline
\end{tabular}

Shading is the highest percentage of responses *Multiple response question

소비자조사 결과 모유수유 기간은 1 년 이상이 가 장 많았고, 외출 시 모유 수유하는 경우는 자주 있다 라고 응답한 사람이 $41.1 \%$ 로 높게 나타났다. 수유브래 지어를 착용해 본 경험이 있다고 응답한 사람은 $98.0 \%$ 로 대부분의 사람들이 착용해본 적이 있는 것으로 나 타났다. 조사 대상자의 $90 \%$ 이상이 임산부 · 수유 브 래지어와 일반 브래지어의 구분이 필요하다라고 응 답했으며, 일반 브래지어를 착용하고 수유했을 때의 만족도는 $80 \%$ 이상이 불편하다고 응답해, 수유 브래 지어의 필요성이 강조되었다.

임산부 - 수유 브래지어를 주로 구입하는 장소는 인터넷(온라인쇼핑몰)이 $58.4 \%$ 로 가장 높게 나타났 으며, 보유하고 있는 수유브래지어의 종류로는 어깨 수유구형, 컵내부 수유구형, 랩형, 앞중심 수유구형 순으로 나타났다. 임산부 - 수유 브래지어를 구입 또 는 착용한 이유로는 수유 시 브래지어 착 - 탈의 편리 성을 위해서 라는 응답이 $76.4 \%$ 로 가장 높게 나타났 으며, $\mathrm{Bae}(2002)$ 와 Choi et al.(2000)의 연구에서 모두 동일한 결과가 나타났다. 이에 따라 수유브래지어 제 작 시 개폐 부위(패스너)의 설계가 중요할 것으로 생 각된다. 임산부 - 수유 브래지어 구매 시 고려 요인으 로는 수유기간과 임신기간 모두 착용감을 가장 중요 
시 하였으며, 와이어가 없고 풀컵 또는 $3 / 4$ 컵, 색상은 스킨색상을 가장 선호하는 것으로 나타났다. 이와 같 이 임신시기 및 산후에 착용감을 중요시하고, 착탈의 의 편리성을 중요시하는 결과는 임부복 디자인을 연 구한 Jang and Park(2015)의 연구와 유사한 결과이다.

기존의 수유 브래지어 사용 시 가슴을 잘 받쳐준 다, 가슴을 잘 모아준다, 디자인이 다양하다의 항목에 서 불만족하는 것으로 나타났는데, Choi et al.(2000) 의 연구에서도 디자인이 다양하다는 항목에서 $56.2 \%$ 로 불만족 정도가 높게 나타난 것으로 보아, 여전히 수유 브래지어의 디자인이 개선되지 않고 있다는 것 을 알 수 있었다. 수유브래지어의 기능에서는 유방 받쳐주기, 유방 압박하지 않기, 수유 시 패스너 열고 닫기, 땀이나 젖 흡수하기의 착용 효과가 중요한 것 으로 조사되었다. $\mathrm{Bae}(2002)$ 의 연구에 따르면 패스너 의 종류에는 크게 내측, 외측, 상단 트임으로 나눌 수 있는데, 내측 트임은 유방의 노출이 많고, 상단 트임 은 유방의 노출은 적으나 아기 얼굴이 브래지어에 닿 는 등의 문제점을 지적하였다. 이에 따라 유방의 노출 을 최소화하고 아기의 피부에 영향을 주지 않는 임산 부·수유 브래지어의 설계가 필요할 것으로 사료된 다.

본 연구는 젖가슴둘레와 젖가슴아래둘레의 치수를 조사 대상자가 직접 측정하여 작성하도록 하였기 때 문에 오차의 가능성이 있다는 제한점이 있다. 따라서 연구자가 직접 신체치수를 측정하는 방법을 통한 임 산부 - 수유 브래지어의 사용실태를 조사할 필요가 있을 것으로 사료된다.

\section{References}

Bae, H.-S. (2002). Status quo study on the using of the nursing brassiere. Journal of Human Ecology, 6, 17-27.

Carriwell. (n.d.). Carriwell drop cup nursing bra. Mamiz, Retrieved April 25, 2016, from http://www. mamiz.co.kr/shop/goods/goods_view.php?goodsn $\mathrm{o}=224 \&$ category $=007002$

Cho, S.-H. (2006). Brassiere pattern development based on $3 D$ measurements of upper body and breast shape: Focused in their 30's women. Unpublished doctoral dissertation, Kyung Hee University, Seoul, Korea.

Choi, H. S., Choi, J. H., \& Kim, S. R. (2000). A study of the development of nursing brassiere. Journal of the Korean Society of Clothing and Textiles, 24(6), 918-927.

Choung, K. W. (1995). A study on breast shape properties for maternity brassiere designing. Unpublished master's thesis, Ewha Womans University, Seoul, Korea.

Chung, K.-W., \& Choi, H.-S. (1996). A study on transformation of the breast size, shape and volume properties for design of maternity brassiere. Journal of the Korean Society of Clothing and Textiles, 20(3), 438-451.

Inujirushi. (n.d.). Inujirushi flower pattern nursing bra. Mamiz, Retrieved April 25, 2016, from http:// www.mamiz.co.kr/shop/goods/goods_view.php?g oodsno $=91$ \& category $=007006$

Jang, H.-C., \& Park, S.-K. (2015). A study on the one-piece dress design wearable during pregnancy and post-natal period. The Research Journal of the Costume Culture, 23(2), 337-352. doi:10.7741/ rjcc.2015.23.2.337

Ko, H. J. (2009). All that underwear. Seoul: Sigongsa. Kim, J. E. (2016, January 11). [2014 국민건강통계] 완전모유수유율 생후 6 개월후부터 $50 \%$ 밑으로 하락 [2014, National Health Statistics: Total breastfeeding rate dropped below 50\% from 6 months of age]. Newsis, Retrieved October 10, 2016, http:// www.newsis.com/ar_detail/view.html?ar_id=NIS X20160111 0013829681\&cID=10201\&pID=10200

Korea Association of Health Promotion. (1998). 유방 질환: 유방의 구조와 기능 [A breast disease: Structure and function of breast]. 건강소식 [Health News], 22(8), 11-12.

Korean Breast Cancer Society(KBCS). (2005). The breast. Seoul: Iljokak.

Korean Society of Obstetrics and Gynecology(KSOG). (2007). Obstetrics. Seoul: Gunjachulpansa.

Lee, S. D. (2002). Breast cancer. Seoul: Hongsinmun- 
hwasa.

Lee, Y. M. (2009). Lingerie style book. Seoul: Brenz.

Lee, Y. S., Park, J. S., Lee, H. K., \& Park, Y. J. (2014). Maternity \& women's health nursing II (3rd ed.). Seoul: Hyunmoonsa.

Motherpia. (n.d.a). 출산전후겸용브라 [Bra for both before and after childbirth]. Venus-eshop, Retrieved April 25, 2016, from http:/www.venus-eshop.co.kr/ WINTERMANGO/Product/WebDetail?contentid= 1511

Motherpia. (n.d.b). 유방의 변화 [Change of breast]. Retrieved October 1, 2016, from http://www. motherpia.co.kr/change/change.php?ctg=1

Mothersbaby. (n.d.). Cotton wrap nursing bra. Babizmall, Retrieved April 25, 2016, from http://www. babizmall.co.kr/product/detail.html?product_no $=2$ $06 \&$ cate_no $=225 \&$ display_group $=1$

Shim, E.-J., \& Kim, S.-R. (2006). A study on the design development of a maternity wear combined with nursing. Journal of Fashion Business, 10(2), 147-165.

Son, H. J. (2006). Pattern cutting for lingerie. Seoul: Kyungchunsa. 